\title{
INDUSTRIAL WASTEWATER TREATMENT, RECYCLING, RECOVERY.
}

\author{
Pär Bragsjö \\ Mercatus Engineering $A B$, Sweden
}

\section{PLANNING AND POLICY}

We are specialists at plants and systems for recirculation, purification, and recycling of industrial water and waste water. Our systems are continuously being adapted and developed, and with our wide selection and the knowledge base we have developed during a good twenty years, we can guarantee continuity and quality. We strive to achieve that our quality will be so high and enduring that it will substantially contribute to new customers and contracts, today and in the future.

Our environmental efforts are an important component of our operation, determined by our own ethic values as well as ever stronger market and legal demands. For us it is obvious we must safeguard the environment.

Mercatus is actively working to reduce the operation's negative environmental effects to a minimum. Consideration for the environment will be taken with each decision and environmental efforts will be developed in terms of new knowledge and technology. We will see measures that improve the environment as long-term investments.

Everyone at the company participates in this environmental effort. We are demanding our suppliers so they are stimulated to provide us the most environmentally friendly products and services possible.

We wish to encourage openness and dialogue among co-workers, customers, the authorities and the public regarding environmental issues.

Of course we abide by the applicable laws and regulations that affect us in our operation.

We are working according to ISO9000 and during the spring 1999 we are going to get certificated according to ISO14000.

\section{PRESENTATION OF THE COMPANY}

Mercatus Engineering AB was formed in 1973. Our main working field is treatment systems for water, waste water and process liquids. We offier standard systems, custom designed systems, turn-key plants, pilot tests and service. Some of our products are: 
- Nanofilter

- Ultrafilter

- Microfilter

- Reverse osmosis

- Ion exchanger

- Coolant filtration units

Our lines of business are:

- Lacquering

- Surface finishing

- Printing works

- Textile industry

- Reception plants

- Metal workshops

Some of our customers:

- SAAB Automobile

- Sandvik

- Alfa Laval

- Volvo

- Waste Management

- $\mathrm{ABB}$

- Ericsson

- Scania

- Ford

- ASSI@Domän

- SAAB Aircraft
- Electronic industry

- Enamelling plants

- Vehicles service

- Energy plants

- Wrapping paper

- Shipyards
- SSAB

- Viktor Hasselblad

- Tetra Pak

- Grundfos

- Hitachi

- SKF

- GM

- VolksWagen

- Electrolux

- Whirlpool

- Bosch

\section{MEMBRANE SEPARATION TECHNIQUES}

Membrane filter are most commonly used in a method of filtration known as "cross-flow filtration". As opposed to conventional "dead-end" filtration where feed flow is normal or 908 to the surface of the filter medium, cross-flow filtration, or "tangential-flow filtration" (TFF) as it is sometimes called, has the feed flow parallel to the filtration medium. The advantage of this technique is to minimisation of any build-up retained materials on the surface of the filter medium. 

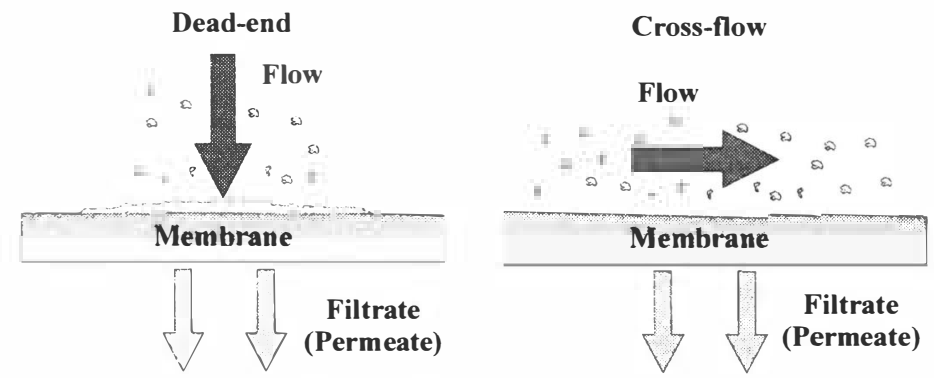

Picture 1: The difference between dead-end and cross-flow.

At Mercatus we are using four different filter techniques.

- Reverse osmosis

- Nanofilter

- Ultrafilter

- Microfilter

The most common techniques are reverse osmosis and ultra filtration. The diffierence between them can be visualised in the pictures mentioned below.

\section{Reverse osmosis}

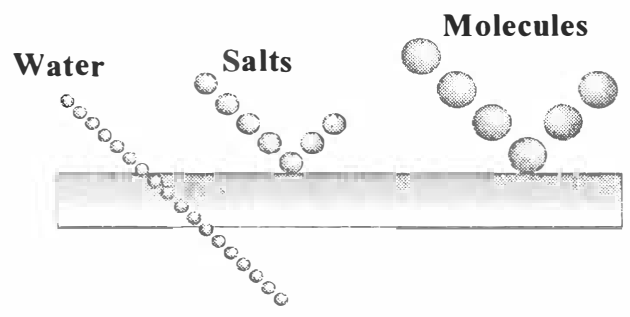

Picture 2: Reverse osmosis. 


\section{Ultra filter}

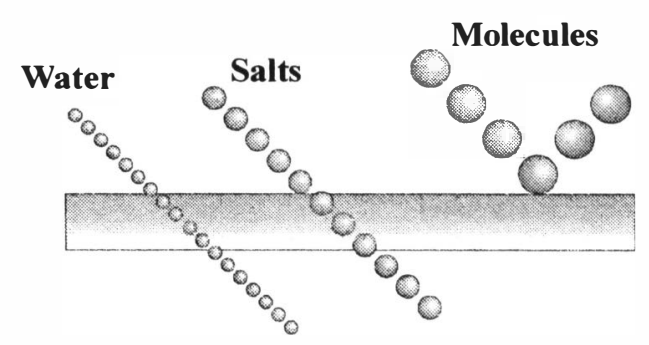

Picture 3: Ultra filter.

Nano filter is something between reverse osmosis and ultra filtration. Micro filtration is used for separating suspended materials from water.

Some areas of application for our filter plants are for example:

- Water-based coolants and lubricants

- Release agent and coolant

- Emulsions for indicating cracks

- Degreasing bath and rinsing water

The picture stated below shows a typical application for ultra filter. 
Continous recycling
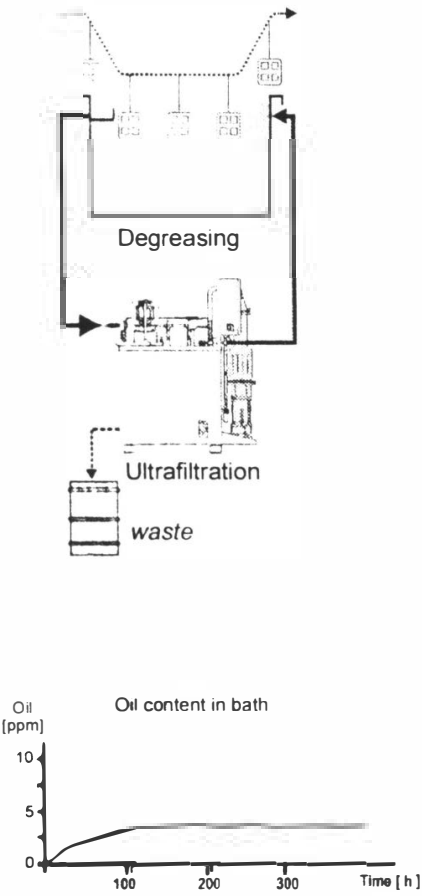

Without recycling
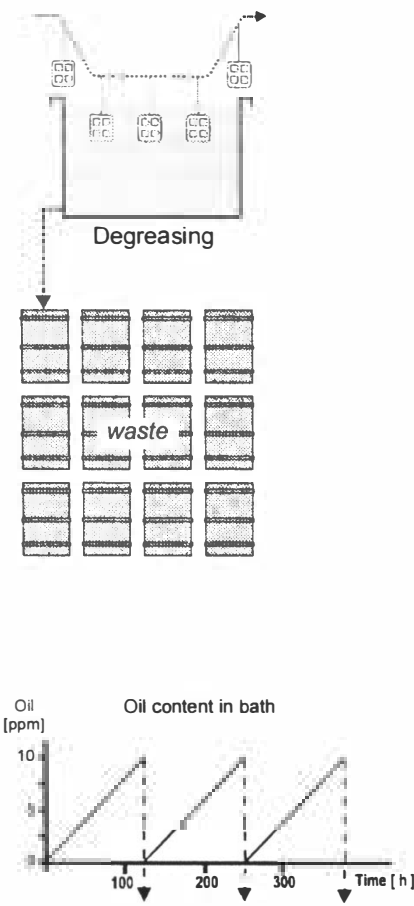

Picture 4. Degreasing bath, recycling with ultra filter.

\begin{tabular}{|l|l|l|}
\hline Example & With UF & Without UF \\
\hline Wastewater per year & $8 \mathrm{~m}^{3}$ & $2000 \mathrm{~m}^{3}$ \\
\hline Detergent saving & Appr. 70\% & - \\
\hline Max. oil in bath & $3 \mathrm{~g} / \mathrm{l}$ & $10 \mathrm{~g} / \mathrm{l}$ \\
\hline
\end{tabular}

Table 1: Degreasing bath, with or without ultra filter. 


\section{SELECTIVE ION EXCHANGER TECHNIQUES}

Water to be treated is conducted through ion exchanger resin filter columns. The resin is made of synthetic, insoluble, three- dimensional polymers which posses ion exchanger properties. The granular size is approximately $0,5 \mathrm{~mm}$. Selective ion exchanger have a high level of affinity to heavy metals. This means that they form stronger chemical bonds with heavy metal ions than they do with harmless substances, such as sodium and calcium. This selectivity gives the resin high total capacity, combined with small eluate volume ( eluate $=$ ion exchange concentrate $)$. Typically, concentrations after selective ion exchange are within the ppb range. Saturated resin is regenerated with use of acid/alkaline. The eluate contains the separated metal in a concentrated form. After regeneration the resin is ready for use again. The resin is divided among two or three filter vessels, arranged in a series. In regeneration, the arrangement is changed so that the water passes the cleanest resin, last ( "merry-go-round"-system ). This system allows regeneration without operation interruption.

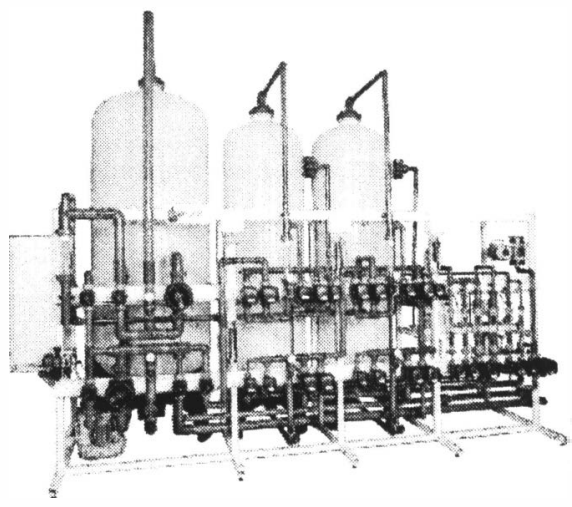

Picture 2: Selective ion exchanger with sand filter.

Some areas of application for our selective ion exchanger plants are for example:

- "End-of-pipe" purification of wastewater with heavy metal contamination.

- Final purification after ultra-filter, evaporation sand filtration and precipitation plants.

- Cleaning of flue gas condensate. 


\section{COOLANT FILTRATION UNITS}

Our filter plants are used for cleaning cooling lubricants.

Different requirements and fields of application shall determine which plants will be used by you. The filter plants can be erected as central plants for machine groups or entire production areas or, alternatively, as single plants.

The most common plants are the cyclone filter unit and rotating vacuum filters.

\section{Cyclone filter unit}

This type of coolant filtration unit is suitable for removing sedimenting solids from liquids of low viscosity such as water and emulsions.

Due to tangential streaming-in of the liquid, a primary swirl develops. The heavier particles in the liquid, due to centrifugal force, are pressed to the wall of the cyclone housing. Due to the tapering of the conical cyclone housing, a secondary swirl develops in the lower area which leads the cleaned cooling lubricant back in opposite direction. The dirt particles, together with small amount off liquid (approx. 1,5 $\mathrm{l} / \mathrm{min}$ ), are removed through the underflow nozzle.

The throughput for one cyclone is $90 \mathrm{l} / \mathrm{min}$. The filterunit can be equipped with as many cyclones as the required throughput for the machine (machines).

\section{Rotating vacuum filter}

This type of filter is suitable for cleaning cooling lubricants, emulsions and cutting oils without filter residues. A vacuum pump which has been directly connected with the internal chamber of a filter drum sucks the medium into the interior of the drum. In doing so, the dirt particles on the surface of the filter drum are kept back by means of a superfine filter mesh. Due to the resistance of the accumulating filter cake, the vacuum rises. When an adjustable vacuum is reached, the drum rinsing occurs automatically. An installed scraper chain discharges the sludge.

The plant can be controlled via a SPC system or directly from the processing machine. 
ECOLOGICAL TECHNOLOGY AND MANAGEMENT

KALMAR, SWEDEN, September 22-24, 1999

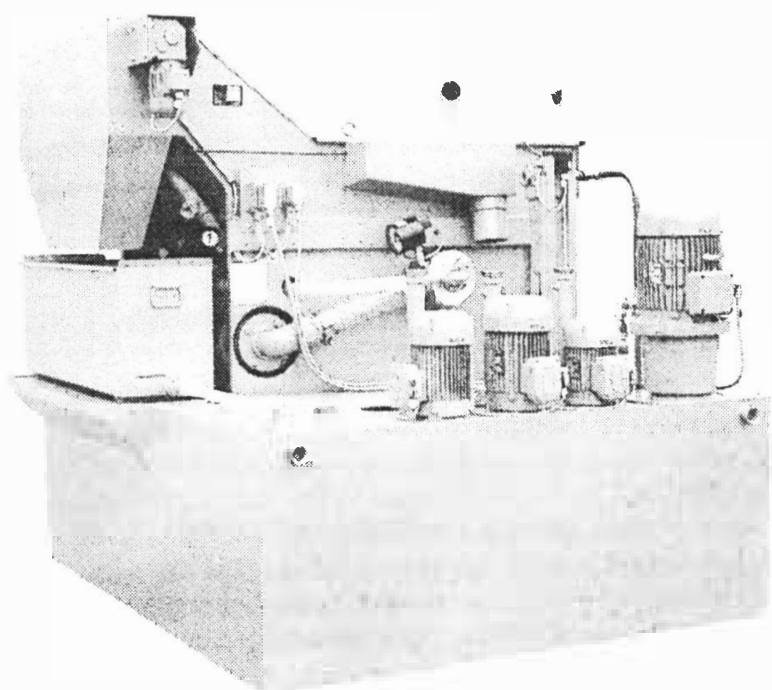

Picture 3: Rotating vacuum filter, throughput $300 \mathrm{l} / \mathrm{min}$. 